\title{
A EXPANSÃO DO ENSINO SECUNDÁRIO NA BAHIA (1942-1961)
}

\author{
Sara Martha Dick (UFBA)* \\ https://orcid.org/0000-0001-8965-7380
}

\section{RESUMO}

Este artigo busca discutir a expansão do ensino secundário na Bahia durante o período compreendido entre os anos de 1942 e 1961. Com seu início no ano de 1836, o Ensino Secundário baiano contava com o Liceu Provincial na Capital, que em 1895 passou a chamar-se Ginásio da Bahia, e com a Reforma Capanema, de 1942, Colégio da Bahia, permanecendo como o único estabelecimento em Salvador até 1947. Objetivamos demonstrar que o início de expansão ocorre a partir do governo de Otávio Mangabeira, eleito democraticamente. Utilizamos das fontes do Arquivo Público da Bahia (APBA), Instituto Geográfico e Histórico da Bahia (IGHBA), Biblioteca Pública da Bahia (BPBA) e Arquivo Municipal de Salvador, além da consulta aos Jornais A Tarde e Diário de Notícias. As fontes foram analisadas, chegando à conclusão de que o período mais democrático contribuiu para a expansão.

Palavras-chave: Ensino secundário. História da educação. Bahia.

\section{ABSTRACT}

\section{THE EXPANSION OF SECONDARY EDUCATION IN BAHIA (1942-1961)}

This article seeks to discuss the expansion of secondary education in Bahia, during the period from 1942 to 1961 . With its beginning in the year of 1836 the Secondary Education of Bahia had the Provincial High School in the Capital, which in 1895 was renamed Ginásio da Bahia and the Capanema Reformation of 1942 Colégio da Bahia, remaining as a single establishment in Salvador until 1947. We aim to demonstrate that the beginning of expansion occurs from the democratically elected government of Otávio Mangabeira. We used the sources of the Public Archive of Bahia - APBA and the Geographic and Historical Institute of Bahia - IGHBa and Public Library of Bahia - BPBa and the Municipal Archive of Salvador, in addition, consultation of the Newspapers: A Tarde and Diário de Notícias. The sources were analyzed, concluding that the most democratic period contributed to the expansion.

Keywords: Secondary education. History of education. Bahia.

Doutora em Educação pela Universidade Federal da Bahia (UFBA). Professora Titular da Faculdade de Educação da Universidade Federal da Bahia (FACED/UFBA). E-mail: saramarthadick@hotmail.com 


\section{RESUMEN \\ LA EXPANSIÓN DE LA EDUCACIÓN SECUNDARIA EN BAHIA (1942-1961)}

Este artículo busca discutir la expansión de la educación secundaria en Bahía, durante el período de 1942 a 1961. Con su inicio en 1836, la Educación Secundaria de Bahía tenía la Escuela Secundaria Provincial en la Capital, que en 1895 pasó a llamarse Ginásio da Bahia y la Reforma Capanema de 1942 Colégio da Bahia, permaneciendo como un solo establecimiento en Salvador hasta 1947. Nuestro objetivo es demostrar que el comienzo de la expansión se produce desde el gobierno democráticamente elegido de Otávio Mangabeira. Utilizamos las fuentes del Archivo Público de Bahía - APBA y el Instituto Geográfico e Histórico de Bahía - IGHBa y la Biblioteca Pública de Bahía - BPBa y el Archivo Municipal de Salvador, además de la consulta de los Periódicos: A Tarde y Diário de Notícias. Se analizaron las fuentes y se concluyó que el período más democrático contribuyó a la expansión.

Palabras clave: Educación secundaria. Historia de la educación. Bahía.

\section{Introdução}

Este artigo busca discutir a expansão do ensino secundário público na Bahia durante o período de 1942 a 1961. O Ensino Secundário público baiano tem seu início no ano de 1836, após a implantação da Lei no 16 , de 12 de agosto de 1834 (BRASIL, 1834). Conhecida como Ato Adicional de 1834, autorizou que as Assembleias Provinciais pudessem legislar sobre a educação primária e secundária. Assim, tratou-se de reunir as chamadas aulas maiores em um único prédio, não compondo um curso propriamente, tendo em vista serem ministradas como aulas avulsas. 0 objetivo inicial declarado era de preparar uma camada intermediária da população para o trabalho na burocracia do Estado, em meio a um processo de formação do Estado Brasileiro muito conturbado do ponto de vista político, econômico e social durante o período regencial. Em relação ao Liceu Provincial, a legislação respondia, a princípio, a uma iniciativa das elites, de acordo com as necessidades de formação de uma camada intermediária da sociedade pronta para atender as exigências urbanas.

As origens das políticas públicas que possibilitaram a implantação do Liceu provincial da Bahia ocorreram em meio ao processo de formação do Estado brasileiro, muito conturbado do ponto de vista político, econômico e social, durante o período regencial.

A primeira metade do século XIX, aquela em que as tensões sociais são aguçadas em decorrência da crise econômica, além da agitação social própria do processo de formação do Estado brasileiro, é o período de elaboração das primeiras iniciativas para o ensino secundário baiano, que se encontrava completamente desorganizado.

O Liceu Provincial foi instituído para reunir as chamadas cadeiras maiores, dispersas por toda a província, centralizando em Salvador, assim, em uma única instituição, o ensino secundário. Contudo, não chegou a atingir o seu objetivo.

As origens das políticas públicas de implantação do Liceu provincial da Bahia, por ocorrer sob o processo de formação do Estado brasileiro, continha as contradições da situação conturbada da Província, em todos os aspectos, durante o período regencial.

Apesar de seus objetivos iniciais de capacitar uma camada da sociedade para o trabalho na burocracia do Estado, o Liceu Provincial Baiano tem uma composição propedêutica, 
com base nas humanidades, com uma estrutura composta de 13 cadeiras:

Geometria e Trigonometria; Gramática Filosófica; Filosofia Racional; Moral; Geografia e História; Latim; Inglês; Grego; Francês; Eloquência; Poesia; Comércio e Contabilidade; Desenho e Pintura, além de incorporar o museu de História Natural.

Essas aulas avulsas existiam tanto na Capital, como também distribuídas em outras cidades como Santo Amaro, Cachoeira, Nazaré, Valença, Ilhéus, Caravelas Itaparica, Rio de Contas, Itapicuru, Vila da Barra, Caetité, Cayru, Inhambupe, Maragogipe, Jaguaribe, vila Nova, Porto Seguro e Jacobina. Entretanto, tais aulas ocorriam sem nenhuma orientação geral quanto ao conteúdo, ao método ou à extensão e intensidade de programas.

Considerando esse panorama inicial do Ensino Secundário público baiano, podemos dizer que o grande problema de organização eram as matrículas por disciplina. Na verdade, não era a organização de um curso, mas, sim, aulas avulsas soltas que não tinham organicidade. Desta forma o ensino secundário segue durante o século XIX.

Em 1860 foi proposto pelo Diretor-Geral dos Estudos, João José Barbosa de Oliveira (pai de Ruy Barbosa), um Regulamento Orgânico para a educação baiana, somente regulamentado pela Assembleia Provincial em 1862. Este Regulamento pretende sistematizar a educação baiana, em especial o ensino secundário. Com este Regulamento Orgânico suprimiram-se todas as antigas Aulas Maiores, ou cadeiras avulsas de ensino secundário, existentes não só na capital, como nas cidades e vilas do interior, desde que sua frequência fosse inferior a 15 alunos, concentrando no Liceu os professores das outras cadeiras avulsas de frequência maior, estabelecendo ainda a seriação alemã de nove anos para o bacharelado em Letras do Liceu e seriação de seis anos para o ensino secundário. 0 curso seria dividido em três séries: a 1a , chamada elementar, com dois anos; a $2^{\mathrm{a}}$, de gramática, com três anos; e a $3^{3}$, superior, com três anos e ainda um ano de estudo de Lógica (FARIAS; MENEZES, 1937).

Nesse período as discussões presentes nas falas presidenciais e relatórios sobre a instrução pública dão conta de preocupações como centralizar ou descentralizar a administração do ensino, com vitória das ideias centralizadoras e a criação do cargo de Diretor-Geral de Estudos, que substituiu o Conselho de Instrução Pública existente anteriormente. Tais ideias consideravam que o ensino público gratuito ou ensino pago teriam por objetivo distinguir a frequência no Liceu; assim advogavam um ensino propedêutico para uma elite e um ensino mais prático para o restante da população, como preparação para a vida, e até mesmo ideias que já pregavam a necessidade de nacionalização do ensino.

Em relação ao Liceu Provincial, podemos dizer que, segundo seus objetivos, deveria conferir um ensino secundário até certo ponto terminal, isto é, habilitando as camadas intermediárias a ingressarem diretamente no mercado de trabalho, na maioria das vezes em funções públicas. Todavia, acabava sendo um curso pretensamente preparatório para o ensino superior, sem, no entanto, habilitar para o seu ingresso. Nessa contradição, percebemos que o Liceu Provincial, procurando ter um curso para profissionalizar, a fim de atender à formação de uma burocracia estatal, tem um currículo propedêutico, não conseguindo ser nem uma coisa nem outra.

Daí o porquê da fuga de matrículas para o ensino particular, que era claramente propedêutico e habilitava para o ingresso no ensino superior, enquanto o Liceu sequer conseguia que seus poucos alunos fossem absorvidos pelo mercado de trabalho.

No período que sucede ao Regulamento de 1860 , correspondente às décadas finais do Império, abrangendo os anos de 1860 a 1890 - esse último já republicano -, persistiam os problemas políticos e agravava-se a crise econômica no Nordeste. Do ponto de vista educacional, essa situação se expressa nas diversas 
reformas educacionais e na proliferação das escolas particulares.

Os anos de 1860 a 1870 indicam, também, a derrocada do Império, marcada por uma instabilidade política e econômica, sobretudo em relação ao Nordeste, considerado por Kátia Mattoso (1992) como o período da desagregação da Monarquia. Na educação baiana dos anos 1860, há uma tênue tentativa de sistematização, com o Regulamento Orgânico de 1860/1862, mas que não foi concretizada na prática.

Na década de 1870, intensificou-se o deslocamento do eixo econômico do Nordeste açucareiro decadente para o Centro-Sul cafeicultor, promissor com certo surto industrial. Subjacentemente estão os enfrentamentos à questão da escravidão e a introdução da mão de obra imigrante na lavoura cafeeira no CentroSul do país, e as "novas" tendências políticas, com destaque para o positivismo de Comte e as ideias republicanas, representadas pelo movimento político de Itu.

Nesse período se afirmam as influências de ideias como o liberalismo, do qual deriva o Manifesto Liberal de 1868, ou mesmo a criação do Partido Republicano em 1870. Situação que implicou na proposta de reformas das instituições existentes, em todos os sentidos.

A expressão do pensamento Liberal na educação brasileira foi uma série de reformas ocorridas fundamentalmente a partir da Corte (como a reforma de Leôncio Carvalho), com repercussão em todo o país, indicando a nova face que ia assumindo, aos poucos, o Estado brasileiro, com imensas disparidades regionais.

Para a educação baiana, especialmente no que diz respeito às políticas públicas para o ensino secundário, tal situação se expressava nas propostas de reforma do ensino que, efetivamente, passaram a ocorrer a partir de 1870, seguidas de reformulações e regulamentações em 1873, 1875 e 1881, até a Reforma de 1890, já no Brasil Republicano.

No ano de 1870, novos atos de reforma da educação pública baiana foram emitidos (NU-
NES, 1999, p. 87). É uma reforma que restabeleceu cadeiras no Liceu (de Física e de Química), desmembrou a cadeira de Geografia e História, determinou que os concursos fossem realizados em palácio sob a presidência do Governo. Ao mesmo tempo, tornou incompatível o cargo de professor do Liceu com o de professor da Faculdade de Medicina, atribuiu ao professor de História Natural a direção do Museu, acumulou o cargo de diretor do Liceu com o de Diretor da Instrução Pública, caracterizando o aspecto centralizador desta reforma. Ainda foi criado o bacharelado em Ciências, determinando a preferência dos bacharéis formados pelo Liceu, principalmente os diplomados em Ciências, para os cargos públicos.

Uma nova reforma no ensino baiano, realizada por ato de 27 de setembro de 1873, transforma o Liceu em Instituto de Letras e Ciências, modifica algumas disciplinas (suprime algumas e institui outras), porém, tanto na reforma de 1870 como na de 1873 , permanece a matrícula por disciplina e o aluno pode matricular-se naquelas que mais lhe interessarem (NUNES, 1999).

A Reforma de 1875 retoma as determinações de 1873, mantendo o Instituto de Letras e Ciências, o ingresso de professores por concurso e a matrícula de alunos por disciplina a qualquer tempo (NUNES, 1999).

Na Bahia, em 1880, o presidente Antonio de Araújo de Aragão Bulcão, na fala com que abriu a Assembleia Legislativa em 1으 de maio, afirmava que o estado da Instrução Pública na província - com suas 516 escolas primárias, com cerca de 20 mil alunos, duas Escolas Normais para o preparo de professores, um Liceu com excelente professorado e numerosos colégios, aulas e estabelecimentos particulares, bastante frequentados - ainda estava abaixo dos índices de outras províncias com as mesmas condições da Bahia (BULCÃO, 1881).

Nesse sentido, elaborou o que ficou conhecido como o Regulamento Bulcão, em 1881. Neste regulamento, o ensino público secundário continua restrito ao Liceu Provincial, 
em Salvador, mantendo o Instituto de Letras e Ciências, o ingresso de professores bacharéis e por concurso, e mantendo a matrícula por disciplina (BULCÃO, 1881).

A partir de 1883, inicia-se na Bahia imperial um curso secundário público para mulheres - até então as mulheres se matriculavam em cursos em escolas particulares. No Liceu Provincial estudavam apenas homens. Este curso secundário público feminino funcionou no prédio das escolas primárias, no Centro da cidade de Salvador, e tinha aulas diárias das 17 às 21 horas, ministradas por 12 senhoras da sociedade baiana que aceitaram lecionar por benemerência.

Entretanto, durante toda década de 1880 o ensino feminino público teve um funcionamento descontínuo, sem resultados práticos, com descaso dado à instrução feminina e exiguidade de verba.

\section{0 ensino secundário baiano e a república}

No ano de 1890, foi baixado um ato reformando a instrução pública do Estado da Bahia, buscando conciliar os novos princípios políticos com a educação mais conservadora aceita pela realidade baiana (TAVARES, 1968).

Esse ato era relativo aos ensinos primário e secundário e das escolas Normais de Homens e de Senhoras. Em seguida, dois novos Atos regulavam o ensino secundário geral: um criava o Instituto Oficial de Ensino Secundário, substituindo o antigo Liceu, e outro baixava o respectivo Regulamento. E, em outro Ato, era aprovado o regulamento relativo ao estabelecimento do fundo escolar e imposto de capitação. Este Ato também conservou a formação de um Fundo Escolar, só que redimensionando um pouco. Por outro lado, fez outra reforma educacional inspirando-se bastante no Regulamento Bulcão, sobretudo na forma de classificação das escolas e disciplinas a serem ministradas, mas também utilizando e moderando em alguns pontos de reformas já propostas. A deliberação manteve o Conselho Superior de Ensino, não mais composto de pessoas nomeadas por seu saber pedagógico, mas com membros natos, que, com o cargo que ocupavam ou assumiam, se tornavam obrigatoriamente participantes do Conselho de Ensino, o que levava naturalmente a membros menos diretamente interessados em instrução pública e nem sempre tão atuantes quanto os especificamente escolhidos para a função, por seus méritos docentes ou interesses educativos (DICK, 2001).

0 Ato de 1890 estabelece dois tipos de ensino secundário: aquele relativo ao Liceu e às escolas normais, e outro com caráter técnico, voltado para profissionalização.

Contudo, a implantação de tal ato encontra muitas dificuldades, levando o Diretor da Instrução Pública, Satyro Dias, a avaliar a situação no ano de 1894, concluindo não haver avanços, mostrando-se muito preocupado com o ensino elementar. Quanto ao Instituto Oficial de Ensino Secundário, criado em 1890 para substituir o Liceu Provincial Baiano existente desde 1836, considera a necessidade de que acompanhe os programas do Governo Federal, afirmando que seria necessária a observância dos programas nacionais para não ocorrer completo isolamento, sem resultados (DIAS, 1894).

O ensino secundário segue desorganizado até 1895, com a promulgação da Lei no 117 (BAHIA, 1895), que modifica a estrutura do ensino, uma espécie de Lei Orgânica do ensino baiano. Por ocasião da edição da referida Lei, a instituição de ensino secundário passou a ser chamada de Ginásio da Bahia. A partir desta Lei é indicada uma nova divisão para a instrução pública no estado da Bahia, em quatro níveis:

1 - O Primário - composto por escola infantil; Elementar (1ํo grau); Complementar ( $2^{\circ}$ grau);

2 - O Secundário - composto pelo Ginásio (da Bahia);

3 - O Profissional - composto pelos Institutos; escolas de "aplicação" ou cursos profissionais e" technicos"; 
4 - 0 Superior - composto por Universidades em que sejam adotados os planos, programas e regulamentos das faculdades federais semelhantes. (BAHIA, 1895).

Somente com a Reforma da instrução Pública, de 1895, o ensino feminino público passou a fazer parte do "Gymnasio da Bahia”. Todavia, em lugares separados no recinto, com os exames de admissão separados e de conteúdos diferenciados. Mesmo assim, somente em 1900 constam matrículas femininas no Ginásio da Bahia, como mostra a Tabela 1.

Tabela 1 - Matrículas no Ginásio da Bahia - final do Séc. XIX /início republicano

\begin{tabular}{cccc}
\hline ANO & MASCULINO & FEMININO & TOTAL \\
\hline 1896 & 62 & - & 62 \\
1897 & 67 & - & 67 \\
1898 & 142 & - & 142 \\
1899 & 226 & - & 226 \\
1900 & 233 & 4 & 237 \\
1901 & 181 & 9 & 190 \\
1902 & 129 & 6 & 135 \\
1903 & 118 & 7 & 125 \\
1904 & 112 & 7 & 119 \\
1905 & 136 & 11 & 147 \\
1909 & 284 & 44 & 328 \\
1918 & 198 & 10 & 208 \\
1923 & 267 & 67 & 334 \\
1926 & 397 & 105 & 502 \\
1936 & 1012 & 180 & 1192 \\
1937 & 919 & 184 & 1103 \\
1941 & 1480 & 332 & 1814 \\
\hline
\end{tabular}

Fonte: Elaborada pela autora deste artigo com base nos dados de Bahia (1948a, 1950, 1957, 1958).

De acordo com a Lei no 117 (BAHIA, 1895), no seu artigo 32, as disciplinas ministradas eram: língua portuguesa, latim, grego, francês, inglês, alemão, matemática elementar, história universal, geografia, cartografia e história do Brasil, biologia (compreendendo a história natural descritiva e a geologia), física, química, mineralogia e meteorologia, mecânica e astronomia, geometria geral, cálculo, geometria descritiva, literatura nacional e comparada, sociologia, moral, psicologia, lógica, economia política, estatística, direito pátrio. Existiam, ainda, professores para as aulas de desenho, música, ginástica, esgrima, natação e exercícios militares, distribuídas do primeiro ao sétimo ano. Situação que promoveria "o desenvolvimento físico, intelectual e moral do indivíduo, dando-se uma educação integral que o habilite a bem servir à família e à sociedade" (TAVARES,
1968, p. 42-43).

Uma das grandes questões desse estabelecimento de ensino secundário baiano era a reivindicação de equiparação com o Colégio Pedro II do Rio de Janeiro. De acordo ainda com Professor Luis Henrique Dias Tavares, a concentração das disciplinas de humanidades era requerida para, além de buscar seguir a composição do Colégio Pedro II, habilitar os alunos a poderem seguir as carreiras de Direito e Medicina, que era uma "[...] velha reivindicação dos diretores do antigo Liceu Provincial, mestres que passaram boa parte do Império solicitando para o educandário oficial a condição de preparatório para as escolas de Direito e Medicina" (TAVARES, 1968, p. 45).

O período inicial republicano, caracterizado por uma série de reformas educacionais, incluindo o ensino secundário, repercute na 
educação baiana e no seu Ginásio da Bahia que, por uma reivindicação antiga, passa a ser equiparado ao Colégio Pedro II do Rio de Janeiro, dando possibilidade para a elite baiana que lá estudava de ingressar nos cursos de Direito e Medicina.

Os egressos do Ginásio da Bahia passaram a ter privilégios em certos ramos de atividade, compondo uma elite importante na composição do quadro da intelectualidade baiana. Entretanto, a elitização como caracterização importante do período leva também a uma ampliação de escolas particulares, que de maneira geral têm características, na sua maioria, de escolas confessionais.

A despeito das diversas reformas que ocorreram no início do período republicano, por ocasião da Reforma Rivadávia Correia, em 1911, entre outras consequências consideradas prejudiciais para a educação, foi cancelada a equiparação com o Colégio Pedro II de diversos estabelecimentos de ensino oficiais e particulares, dentre eles do Ginásio da Bahia. Somente em 1915 estes estabelecimentos, como o Ginásio da Bahia, voltaram a ser equiparados ao Pedro II, implicando na possibilidade de ingresso no ensino superior (NUNES, 2001).

0 Ginásio da Bahia continuou sendo a única instituição oficial de ensino secundário durante as primeiras décadas do período republicano. Em 1925, com a Reforma da Instrução (TEIXEIRA, 1925), por ocasião da primeira passagem de Anísio Teixeira na Secretaria da Educação baiana, apesar das mudanças promovidas no ensino básico, o ensino secundário foi mantido na única instituição pública, no Ginásio da Bahia.

Os anos de 1930 indicam mudanças para o ensino secundário no país, repercutindo nos diversos estados, como no Ginásio da Bahia. Como a Reforma de Francisco Campos, em 1931, composta por vários Decretos, entre eles o Decreto no 19.890, de 18 de abril de 1931 (BRASIL, 1931), que estruturou o ensino secundário. 0 objetivo era transformar o ensino secundário, buscando superar a característica exclusivamente propedêutica a fim de contemplar uma função educativa, moral e intelectual do jovem.

Durante o Estado Novo, com as características autoritárias, próprias da ideologia fascista, o Secretário da Educação da Bahia, Isaias Alves, devido à grande necessidade provocada pela demanda do ensino secundário, decide pela ampliação das matrículas no Ginásio da Bahia, que por falta de espaço passou a funcionar em três turnos. São ampliadas as matrículas em vários turnos, sem, porém, pensar em aumentar o número de estabelecimentos públicos para o ensino secundário.

Dessa forma, o ensino secundário público continua somente no Ginásio da Bahia, em Salvador. Em contrapartida, em algumas cidades do interior baiano temos o seguinte momento das instituições privadas: o curso secundário em apenas um estabelecimento nos municípios de Jacobina, Itabuna, Senhor do Bonfim, Cachoeira, Barra, Alagoinhas, Feira de Santana, Santo Amaro e Caetité. Os municípios de Ilhéus e Nazaré possuíam, cada um deles, dois estabelecimentos de ensino secundário particulares.

\section{Reforma Capanema - 1942}

Após a Reforma Capanema - Decreto-lei no 4.244, de 9 de abril de 1942 (BRASIL, 1942) -, o único colégio público de ensino secundário na Bahia passou a ministrar o curso em dois ciclos, conforme determinado pela Lei Orgânica: o ginasial, com duração de quatro anos, e o segundo, curso clássico e científico, com duração de três anos cada. A legislação determinou, ainda, que os estabelecimentos de ensino secundário fossem de dois tipos, o ginásio e o colégio, e não podiam adotar outra denominação. De tal forma que o Art. 6음 da referida Lei dispunha: "Os estabelecimentos de ensino secundário não poderão adotar outra denominação que não a de ginásio ou de colégio." (BRASIL, 1942). E no Art. 7o․ "Ginásio e Colégio são denominações vedadas a estabelecimentos de ensino. não destinados a dar ensino secundário." (BRASIL, 1942). 
Em 1943, após a Reforma Capanema de 1942, o único colégio público de ensino secundário na Bahia passou a denominar-se Colégio da Bahia, ministrando o curso em dois ciclos: o ginasial, com duração de quatro anos, e o segundo - curso clássico e científico -, com duração de três anos cada.

O ensino secundário baiano permaneceu somente em um único estabelecimento público, Colégio da Bahia, em Salvador, até 1947, quando é desdobrado em mais três ginásios públicos na capital.

Esse desdobramento se deu em razão de o Colégio da Bahia não ter mais condições de comportar o número de matrículas demandadas. Neste sentido, foram desdobradas mais três seções, em três bairros diferentes, para atendimento dos alunos de diversos bairros de Salvador, a saber:

- na Liberdade, o Colégio Duque de Caxias;

- em Nazaré, o colégio Severino Vieira;

- em Itapagipe, o Ginásio João Florêncio.

Com a determinação da Lei, as instituições de ensino já existentes, na maioria escolas particulares, para atender ao dispositivo legal, solicitaram ao governo alteração de suas denominações em conformidade com o tipo de ensino secundário que ofereciam. No ano de 1945, a Bahia contava com dez colégios em sua maioria absoluta confessionais, além do Colégio Estadual da Bahia e 17 Ginásios, todos particulares. Poucos municípios tinham a presença de ginásios, perfazendo um total de oito, como vemos no Quadro 2.

Quadro 1 - Colégios existentes na Bahia em 1945

\begin{tabular}{|l|c|c|}
\hline \multicolumn{2}{|c|}{ COLÉGIOS } & Salvador \\
\hline 1 - Colégio Antônio Vieira & Confessional & Salvador \\
\hline 2- Colégio Estadual da Bahia & Estadual & Salvador \\
\hline 3- Colégio Carneiro Ribeiro & Estadual & Salvador \\
\hline 4- Colégio Dois de Julho & Confessional (Presbiteriano) & Salvador \\
\hline 5- Colégio Ipiranga & Particular & Salvador \\
\hline 6- Colégio N. S. das Mercês & Confessional & Salvador \\
\hline 7- Colégio N. S. da Vitória & Confessional & Salvador \\
\hline 8- Colégio Santíssimo Sacramento & Confessional & Salvador \\
\hline 9- Colégio São Salvador & Particular & Salvador \\
\hline 10- Colégio Sofia Costa Pinto & Particular & Feira de Santana \\
\hline 11- Colégio Santanópolis & Particular & . \\
\hline
\end{tabular}

Fonte: Elaborado pela autora deste artigo com base nos dados da Revista Brasileira de Estudos Pedagógicos (1945).

Quadro 2 - Ginásios existentes na Bahia em 1945

\begin{tabular}{|l|c|l|}
\hline \multicolumn{2}{|c|}{ GINÁSIOS } \\
\hline 1- Ginásio Baiano de Ensino & Particular & Salvador \\
\hline 2- Ginásio D. Macedo Costa & Particular & Salvador \\
\hline 3- Ginásio Instituto Normal & Estadual & Salvador \\
\hline 4- Ginásio N. s. Auxiliadora & Confessional & Salvador \\
\hline 5- Ginásio N. S. de Lourdes & Confessional & Salvador \\
\hline
\end{tabular}




\begin{tabular}{|l|c|c|}
\hline 6- Ginásio N. S. da Soledade & Confessional & Salvador \\
\hline 7- Ginásio Salesiano & Confessional & Salvador \\
\hline 8- Ginásio Santa Bernadete & Confessional & Salvador \\
\hline 9- Ginásio São José & Confessional & Salvador \\
\hline 10- Ginásio Conquista & Particular & Vitória da Conquista \\
\hline 11- Ginásio Municipal de Ilhéus & Municipal & Ilhéus \\
\hline 12- Ginásio N. S. da Piedade & Confessional & Ilhéus \\
\hline 13- Ginásio Taylor Egídio & Particular & Jaguaquara \\
\hline 14- Ginásio de Jequié & Particular & Jequié \\
\hline 15- Ginásio Clemente Caldas & Particular & Nazaré \\
\hline 16- Ginásio Santoamariense & Particular & Santo Amaro \\
\hline 17- Ginásio Sagrado Coração & Confessional & Senhor do Bonfim \\
\hline
\end{tabular}

Fonte: Elaborado pela autora deste artigo com base nos dados da Revista Brasileira de Estudos Pedagógicos (1945).

O desdobramento que ocorreu no Colégio da Bahia, em mais três sessões de bairro (na Liberdade, em Nazaré e em Itapagipe), foi devido ao fato de não ter mais condições de comportar o número de matrículas demandadas.

\section{Início de expansão}

Apesar da criação dessas três sessões do ensino secundário público, era grande o número de jovens que desejavam ingressar neste nível de ensino. Tal fato fez com que os pais procurassem o Jornal A Tarde solicitando providências para que seus filhos não ficassem sem estudar, visto que tinham passado do ginásio e não encontravam vagas no clássico nem no científico, pois as escolas particulares não podiam oferecer tal segmento até terem a autorização do Ministério da Educação.

Os problemas do ensino secundário iam além da falta de vagas na rede pública, pois, conforme notícias da época, as escolas também padeciam de falta de água, possuíam vidros quebrados e mobiliários danificados etc. Essa realidade demonstrava a falta de atenção do governo com as escolas mais afastadas do Centro. Portanto, o que poderíamos chamar de expansão foi se dando de modo precário, com entraves e absurdos que foram comprometendo o seu desenvolvimento.

No ano de 1945, uma vez que o ensino secundário público estava restrito à capital, no interior baiano tivemos os seguintes colégios de ensino secundário: Ginásio Conquista, em Vitória da Conquista; Colégio Santananópolis, em Feira de Santana; Ginásio Municipal de Ilhéus, em Ilhéus; Ginásio N. S. da Piedade, em Ilhéus; Ginásio Taylor Egídio, em Jaguaquara; Ginásio de Jequié, em Jequié; Ginásio Clemente Caldas, em Nazaré; Ginásio Santamarense, em Santo Amaro; e Ginásio Sagrado Coração, em Senhor do Bonfim.

De acordo com Edvaldo M. Boaventura (1977), até 1947, a Bahia só podia contar com um colégio secundário oficial, o Colégio Estadual da Bahia, o atual Instituto Central de Educação Isaías Alves, e duas Escolas Normais Rurais, uma em Caetité, zona da Serra Geral, e outra em Feira de Santana. "Tudo isso não somava 2.000 matrículas, oferecidas pelo poder público estadual.” (BOAVENTURA, 1977, p. 48-49).

O curso ginasial também foi instituído no Instituto Normal da Bahia com um número significativo de matrículas, que, de acordo com Relatório do Interventor Onofre Pinto Aleixo 
(1945), contava com 529 alunos no curso secundário e 1.313 alunos no Ginásio, enquanto o Colégio da Bahia possuía 709 alunos no total. Segundo Relatório do Interventor Federal Onofre Aleixo, que substituiu Landulfo Alves na Bahia, o Instituto Normal possuía melhores condições de funcionamento (ALEIXO, 1945, p. 67).

De acordo com tal Relatório, mesmo com as possíveis intervenções para melhorar a situação do Colégio da Bahia, "[...] muito há ainda o que fazer no tocante a seu aparelhamento e ampliação de suas instalações, já que o momento não permite a construção de novo edifício" (ALEIXO, 1945, p. 67).

Apesar do desdobramento do Colégio da Bahia em outros três ginásios, o ensino secundário público ainda ficava concentrado na capital, sem iniciativas públicas para esta modalidade de ensino no interior do estado, exceção feira ao Ginásio Municipal de Ilhéus.

Como Secretário da Educação e Saúde da Bahia por mais de uma vez, e diante da situação do ensino secundário baiano, Anísio Teixeira escreveu que "cumpria organizar seu sistema de ensino médio ou secundário" (TEIXEIRA, 1949).

No Relatório do então Secretário da Educação e Saúde da Bahia, em 1948/1949, Anísio Teixeira, ao propor uma reformulação da educação baiana, referia-se desta forma sobre o ensino secundário:
A criação, no interior do Estado, de Centros Regionais de Educação secundária, normal e profissional, impõe-se por vários motivos, além da necessidade virtual de sistematizar as oportunidades educativas oferecidas pelo Poder Público. Com efeito, se o problema da educação fundamental comum do povo, isto é, a educação primária, é o problema máximo no campo do ensino público, não se deve esquecer que sua solução depende, essencialmente, da existência dos outros graus de ensino, e sobretudo, da eficiência dêsses outros graus e ramos. Por outro lado, a concentração do ensino post-primário nas capitais, sobretudo no Norte do Brasil, vem acentuando a gravitação, cada vez mais intensa, das populações para essas cidades, com a dupla consequência do seu congestionamento e, o que é pior ainda, da formação de uma massa de diplomados que não podem elas próprias absorver, e que também não podem devolver às zonas do interior, por haverem os diplomados perdido o gôsto da vida mais frugal e menos confortável dessas regiões. (TEIXEIRA, 1949).

O final dos anos de 1940, bem como da década de 1950, representou para o país um grande aumento populacional, deslindando os enormes desequilíbrios entre as regiões e as desigualdades sociais, com grande crescimento da população urbana. Neste contexto de questões políticas, sociais e econômicas, aguçam-se as tensões que desnudam os problemas existentes na sociedade.

Tabela 2 - Alunos no ensino secundário oficial (1948-1950)

\begin{tabular}{cccc}
\hline ANO & $\begin{array}{c}\text { ESTABELECIMENTO } \\
\text { OFICIAL }\end{array}$ & $\begin{array}{c}\text { ESTABELECIMENTO } \\
\text { PARTICULAR (Bolsa) }\end{array}$ & TOTAL \\
\hline 1948 & 5074 & 101 & 5175 \\
1949 & 5489 & 296 & 5785 \\
1950 & 5692 & 724 & 6416 \\
\hline
\end{tabular}

Fonte: Bahia (1950).

Diante de tais questões, a educação aflorou como um elemento importante no processo de democratização da sociedade, dando partida para a noção da possibilidade de expansão de educação de modo geral, especialmente para o ensino secundário.
É importante destacar que, particularmente na Bahia, o período foi marcado por uma abertura democrática com a eleição para governador de Otávio Mangabeira, no período de 1947 a 1951. Para assumir a Secretaria de Educação e Saúde do Estado da Bahia, o governador con- 
vidou Anísio Spínola Teixeira, que foi o autor da Reforma da Educação baiana de 1925, que ainda estava vigente.

Esse foi, efetivamente, o período que podemos considerar como aquele responsável por um processo de expansão da educação e do ensino secundário na Bahia, que atribuímos ao período de maior democratização no estado.

Estamos considerando como expansão o aumento do número de escolas - e não o número de matrículas -, ainda que pequena a iniciativa pública, mas que demonstra uma forte ligação como período de maior democratização no estado baiano. Cabe salientar que o ensino particular - confessional ou não - foi o que teve mais expressiva presença no estado da Bahia.

Esse, inclusive, foi o período de discussões para elaboração da Constituição do Estado da Bahia, que ocorreu na Assembleia Legislativa. Por ocasião destas discussões, Anísio Teixeira argumentou sobre a importância da educação, assim como reafirmou a necessidade da sua democratização, bem como da vida pública. Afirmava que esta democratização viria a partir da educação (BOAVENTURA, 2000).

Ainda conforme o Professor Boaventura (2000), de acordo com a Constituição Federal de 1946, como disposto no art. 177 do capítulo Da Educação e Culturas, os estados passaram a ter a competência em relação à educação e ensino, através da supervisão e direção do Conselho Estadual de Educação e Cultura.

Apesar de todos esses avanços, após a elaboração da Constituição, foi enviado à Assembleia Legislativa um projeto de Lei Orgânica do Ensino para a adequação da educação baiana aos novos ditames da legislação orgânica elaborada por Capanema.

Mesmo com toda preocupação de Anísio Teixeira com a educação no Estado, não conseguiu lograr êxito na aprovação de uma Lei Orgânica para o ensino baiano. Assim, dedicou-se a estruturar a educação primária no estado, sendo necessário recuperar o ensino primário com prédios escolares aparelhados com aluno e professor. Salientava que "a escola sem prédio é uma demonstração do conceito de 'escola formalidade' ou de escola para mistificar a necessidade de educação da população" (TEIXEIRA, 1949, grifo do autor).

Todavia, desde a data da Constituição de 1947, passando por todo o período dos anos 1950, não houve qualquer discussão sobre o projeto, levando até certo ponto a um desânimo por parte de Anísio Teixeira, que se voltou a criar pequenas escolas nas zonas rurais do estado.

A despeito de o governo determinar uma denominação para os estabelecimentos de ensino secundário, na documentação até o momento pesquisada, encontramos uma pequena diversificação de nomenclatura: ensino secundário, ensino médio, educação pós-primária.

Anísio Teixeira empregava o termo ensino médio e fundamentava que

[...] a escola média, sem deixar de ter perfeita equivalência social e pedagógica, deve à variedade de aptidões humanas. Continua com a escola fundamental ela abrigará àqueles alunos, [...] refinando os seus métodos de trabalho e de estudos e preparando-se para constituir aquela camada de nível médio que irá exercer as atividades de nível qualificado que segue imediatamente a mão de obra comum. (TEIXEIRA, [194-?]).

O educador baiano demonstrava uma preocupação que a escola média formasse o homem de ação e de trabalho para exercer atividades na agricultura, na indústria, no comércio e no serviço público. Criticava a escola média de formar prioritariamente a elite intelectual porque nem todos desejavam ser intelectuais. Os cursos ofereciam uma cultura geral e visavam mais familiarizar os alunos com as técnicas modernas de produção do que com técnicas de trabalho exclusivamente intelectual (TEIXEIRA, 1949).

Por outro lado, o governador Otavio Mangabeira defendia: "Devemos oferecer educação 
pós-primária ou secundária a uma percentagem da população escolar." (BAHIA 1948, p. 10).

0 acesso das classes populares ao ensino secundário, principalmente no interior do estado, foi cada vez mais dificultado, mesmo com iniciativas isoladas em alguns municípios.

Ao mesmo tempo, as cobranças realizadas através de taxas criaram vários problemas, tanto em relação aos exames de admissão quanto à taxa de matrícula, sendo que 83,2\% dos alunos não tinham isenção desta taxa (LIMA, 2003).

0 ginásio da Bahia passa a cobrar taxa em fevereiro para os exames de admissão de $\$ 15,00$ (quinze cruzeiros), assim se já era difícil passar no exame, com a existência da taxa, fica ainda mais difícil para os mais pobres. Além disso, também se cobrava desde 1940, taxa de $\$ 60$ cruzeiros dos quais 40 era para a divisão do ensino secundário e 20 pra caixa escolar do colégio. Isso deixa de existir em 1943 com a proibição da cobrança de qualquer aluno por meio da reforma do ensino secundário de 1942. (COLEÇÃO..., 1943).

Os dados coletados nos jornais da época noticiavam que, devido aos aumentos constantes das mensalidades nos estabelecimentos particulares, havia um grande movimento por parte dos estudantes, que já se organizavam em associações estudantis (O ENSINO..., 1950).

Diante de tais questões, a educação aflorou como um elemento importante no processo de democratização da sociedade, dando a partida para a noção da possibilidade de expansão de educação de modo geral, especialmente para o ensino secundário.

Com relação à expansão do ensino secundário, própria da década de 1950, Clarice Nunes (2000) argumenta que ocorreu pelo estabelecimento de ginásios naquelas localidades onde o ensino secundário não se encontrava presente, ou mesmo pelo "aumento de matrícula nas mesmas unidades escolares e pela criação de novos ginásios em locais onde já havia estabelecimentos de ensino secundário" (NUNES, 2000, p. 46).

Em 1948, Anísio propôs um plano de expansão com vários tipos de escolas nas diversas regiões do Estado, argumentando não ser possível continuar com o tipo de escola vigente, sem condições. Afirmava que os cursos secundários deveriam cumprir com "[...] cultura geral, comercial, doméstica e industrial e se destinam ao preparo das múltiplas elites de uma democracia." (TEIXEIRA, 1949).

A partir da Lei no 130 , de 14 de dezembro de 1948 (BAHIA, 1948b), que dispõe, no seu artigo $1^{0}$ - sobre a criação de ginásios oficiais e subvenção de outros existentes no interior do estado, foram criados Ginásios Oficiais do Estado nas cidades de Alagoinhas, Barra, Barreiras, Caetité, Canavieiras, Feira de Santana, Itabuna, Jacobina, Jequié, Juazeiro, Lençóis, Senhor do Bonfim, Serrinha, Valença e Vitória da Conquista, além de outras que, de acordo com o parecer dos órgãos técnicos competentes, julgavam conveniente considerar centros regionais de educação.

No artigo $4^{\circ}$ da referida Lei (BAHIA, $1948 b$ ) foi estabelecido que os ginásios particulares existentes nas cidades seriam subvencionados na base de seiscentos a mil cruzeiros por aluno gratuito cuja matrícula fosse posta à disposição do Estado, num limite mínimo, para efeito de calcular a subvenção, de três alunos e máximo de seis por mil habitantes da população do município, em cuja sede estejam situados.

As matrículas referentes ao ano de 1950 já representavam a ampliação de novos Ginásios de bairro - Nazaré, Itapagipe e Liberdade.

A estratégia de subvenção de bolsas nas escolas particulares, a partir de 1948, como mostra a Tabela 3, apresentava a seguinte situação de matrículas e estabelecimentos em 1952. 
Tabela 3 - Subvenção de Bolsas - 1952

\begin{tabular}{|l|c|c|c|c|}
\hline \multirow{2}{*}{$\begin{array}{l}\text { Dependência } \\
\text { administrativa }\end{array}$} & \multicolumn{2}{|c|}{ Unidades escolares } & \multicolumn{2}{c|}{ Matrículas } \\
\hline Federal & Ginasial & Colegial & Ginasial & Colegial \\
\cline { 2 - 5 } & 1 & - & 69 & - \\
\hline Estadual & 6 & 2 & 3.175 & 1.463 \\
\hline Municipal & 1 & 1 & 319 & 39 \\
\hline Particular & 51 & 17 & 11.564 & 1.382 \\
\hline Total & 59 & 20 & 15.127 & 2.884 \\
\hline
\end{tabular}

Fonte: Elaborada pela autora deste artigo com base em dados do Instituto Brasileiro de Geografia e Estatística (1953).

Havia sido instituído o ensino ginasial nas Escolas Normais de Feira de Santana e de Caetité, cujas matrículas em 1949 foram, respectivamente, de 77 e 141 alunos, totalizando 218.0 desenvolvimento do Estado contrastava com a incipiente oferta de ensino secundário público que, em 1950, atendia a apenas 6.416 alunos, sendo que 5.692 estavam matriculados nos estabelecimentos oficiais e 724 eram mantidos com recursos públicos em escolas particulares através do sistema de bolsas.

De acordo com a mensagem apresentada pelo governador Otávio Mangabeira em 1950, tivemos os seguintes dados de total de matrículas, incluindo as bolsas.

Tabela 4 - Alunos no Ensino Secundário oficial (1948-1950)

\begin{tabular}{|c|c|c|c|}
\hline ANO & $\begin{array}{c}\text { ESTABELECIMENTO } \\
\text { OFICIAL }\end{array}$ & $\begin{array}{c}\text { ESTABELECIMENTO } \\
\text { PARTICULAR (Bolsa) }\end{array}$ & TOTAL \\
\hline 1948 & 5.074 & 101 & 5.175 \\
\hline 1949 & 5.489 & 296 & 5.785 \\
\hline 1950 & 5.692 & 724 & 6.416 \\
\hline
\end{tabular}

Fonte: Elaborada pela autora deste artigo com base em dados de Bahia (1950).

No Sul do estado, no município de Ilhéus, as classes populares só vieram a ter acesso ao curso ginasial público em 1939, com a construção do Ginásio Municipal de Ilhéus. Para a realização da sua construção foi assegurado o recolhimento de uma taxa de $10 \%$ de todos os impostos municipais. Em 15 de março de 1939, foi inaugurado oficialmente o ginásio municipal com ato solene. Foi considerada uma iniciativa de inestimável valor educacional. Foi o primeiro ginásio do Sul do estado, daí o grande número de estudantes que nele ingressaram.

Em 1953, o Jornal Diário de Notícias dava conta dos seguintes estabelecimentos no interior do estado da Bahia: Ginásio Clemente Caldas, em Nazaré das Farinhas; Ginásio de Jequié, em Jequié; e Ginásio de Serrinha, em Serrinha (A ABERTURA..., 1953, p. 2).

As seguintes unidades escolares foram criadas pela Campanha Nacional de Escolas da Comunidade (CNEC): Ginásio Firmino Alves, em Itabuna; Ginásio Henrique Alves, em Itajuí- 
pe; Ginásio Ubaitabense, em Ubaitaba; Ginásio Padre Ovídio, em Feira de Santana; Ginásio Professor Mata Pereira, em Cruz das Almas; Ginásio Santa Maria Goretti, em Muritiba.

Na Bahia, a atuação da CNEC tem início em 1953, com número significativo de escolas e alunos, que, segundo Silva e outros (2003), no período de atuação, até 1987, possuía 201 do total de 1.187 escolas no país e 77.771 do total de 443.118 alunos.

A Bahia teve uma participação significativa nas ações da Campanha, principalmente no interior do estado, na região do município de Alagoinhas e redondezas. A grande participação de escolas cenecistas no interior baiano indica que foi uma via de privatização adotada pelo Estado brasileiro para a educação.

De acordo com Silva e outros (2003), a instituição CNEC teve uma presença importante na educação brasileira:

[...] compreendendo 529 municípios, 608 escolas, 12.728 professores, com uma matrícula de 209.145 alunos e que tem como projeção atingir, num prazo de 05 anos, um contingente de 60.000 alunos no ensino superior, possuindo, atualmente, 24 faculdades com 20 cursos implantados, 12 já aprovados e 36 em tramitação, totalizando 68 cursos. (SILVA et al., 2003, p. 1).

Estreitamente ligada ao clientelismo, a CNEC atuava junto ao poder político com apoio do Estado brasileiro, podendo ser considerada uma forma de privatização da educação, tendo em vista que, de certa forma, o Estado transfere para a CNEC uma forma de expansão e oferta educacional.

Nesse sentido temos:

A relação da CNEC com o poder público no estado da Bahia, buscando aprofundar elementos que evidenciam a utilização das escolas cenecistas como uma via de privatização da educação, bem como obter um maior aprofundamento no estudo da sua organização e funcionamento, através das especificidades apresentadas por suas escolas; conhecer as suas fontes de financiamento no âmbito dos municípios a serem pesquisados e as atividades desenvolvidas pelas respectivas escolas e suas finalidades. (SILVA et al., 2013, p. 1).
A primeira escola cenecista foi fundada no município de Itabuna. Ideia muito bem aceita pela comunidade, principalmente para os pais, que viam a oportunidade de que seus filhos pudessem cursar o ginásio, tão carente nestas localidades do interior baiano. Assim, poderia haver continuidade dos estudos, mesmo que para tanto tivessem que desembolsar taxas para seu cumprimento,

Além desse fato,

Para as autoridades públicas, as escolas da Campanha representavam uma opção de escola ginasial e secundária menos custosa para os cofres públicos, em virtude de que a própria comunidade contribuía para a manutenção da escola através de donativos e das mensalidades escolares. Portanto, os custos eram repartidos entre a comunidade local, o governo federal, estadual e municipal. (SILVA et al., 2013, p. 2).

No período em que o governo baiano empreende uma tentativa de expansão das escolas secundárias na capital e interior, a ação da Campanha Nacional de Escolas da Comunidade representou um aspecto relevante. No período de 1953, data de sua implantação, até 1964, de acordo com Silva e outros (2003), a CNEC chegou a ter 51 escolas, tendo em torno de 5 escolas fundadas por ano, chegando a Bahia a ter o maior número de escolas cenecistas do período.

No período do governo de Regis Pacheco (1951-1955), havia na Bahia mais os seguintes Ginásios: Ginásio Simões Filho, em Maragogipe; Ginásio Luiz Coelho, em Inhambupe; e o Ginásio Santíssimo Sacramento, em Alagoinhas (confessional) (O GOVERNO..., 1953).

Durante o Governo de Antônio Balbino (1955-1959), o Secretário da Educação, Aloisio Short, em seu relatório de 1956 e 1957, fez comparativos tanto em relação ao aumento de matrículas, como em relação às matriculas do Colégio Pedro II (BAHIA, 1957).

Nesse mesmo ano de 1955, outras instituições escolares foram criadas na Bahia, como o Ginásio de Conquista, em Vitória da Conquista, e Ginásio Estadual Regis Pacheco, Jequié. 
No Relatório de 1957, assim como na Mensagem do Governador Antônio Balbino, o Secretário da Educação Aloisio Short fez uma comparação entre as matrículas do Colégio da Bahia e do Colégio Pedro II (BAHIA, 1957):

- Colégio da Bahia - 1955 - 5.076 / 1956 - 5.617

- Colégio Pedro II - 1955 - 3.673 / 1956 - 4.587

No comparativo sobre as matrículas, os Quadros 3 e 4 mostram a evolução em 10 anos.

Quadro 3 - Total na Bahia

\begin{tabular}{|c|c|c|}
\hline Ano & Unidades & Matrículas \\
\hline 1946 & 48 & 11.584 \\
\hline 1956 & 112 & 37.565 \\
\hline
\end{tabular}

Fonte: Relatório de Aloisio Short Secretário da Educação da Bahia (1957, p. 11-12).

Quadro 4 - No Ensino Oficial

\begin{tabular}{|c|c|c|}
\hline Ano & Unidades & Matrículas \\
\hline 1946 & 5 & 4.349 \\
\hline 1956 & 11 & 14.345 \\
\hline
\end{tabular}

Fonte: Bahia (1957, p. 11-12).

Em 1956, mais duas instituições criadas: o Ginásio de Valença, em Valença, e o Ginásio Afrânio Peixoto, em Lençóis. Em 1958, este ginásio foi elevado à condição de Colégio Regional.

Em 1957 foi instituído, na capital, o Colégio da Polícia Militar em Salvador, também oferecendo cursos de $1^{\circ}$ e $2^{\circ}$ graus (JESUS, 2011).

No ano seguinte, o Governador Balbino afirmava: "[...] Ginásio Duque de Caxias, à Liberdade, que integrava como seção do Colégio da Bahia, foi elevado a Colégio, tornando-se autônomo [...]" (BAHIA, 1958, p. 81).

Na mesma mensagem, o governador ainda indicava a intenção de transformar em Colégio o Ginásio João Florêncio, e integrá-lo ao Curso Pedagógico Alípio Franca (BAHIA, 1958).

Nesse ano de 1958, foram criados no interior do estado, o Ginásio João Muniz, na cidade de Barra, o Ginásio Estadual de Itabuna, em
Itabuna, e o Ginásio Pinto de Carvalho, em Salvador

Na Mensagem de 1958, o Governador da Bahia, Antônio Balbino, indica que ao conjunto de seções do Colégio Central foram acrescidas mais três unidades de bairro: o Ginásio Góes Calmon, no bairro de Brotas; o Ginásio Pinto de Carvalho, no bairro de São Caetano; e o Ginásio Manoel Devoto, no bairro do Rio Vermelho (BAHIA, 1958).

Ainda sobre a necessidade de ampliação dos locais de unidades de ensino secundário, assim se posicionava o Governados Antônio Balbino:

Mereceu interesse especial do Govêrno, atendendo ao ideal de fixar os estudantes que concluem o Curso Ginasial nos locais que lhes servem de residência, a criação de cursos colegiais nas principais cidades do interior. Assim, foram criados os cursos de Colégio de Feira de Santana, Conquista, Jequié, Serrinha, Santo Amaro, Caetité e Cachoeira. (BAHIA, 1958, p. 80).

Ainda no ano de 1958, o governo criou o curso colegial nos ginásios de Feira de Santana, Conquista e Santo Amaro. Além disso, também foi criado o Ginásio Monteiro Lobato, no bairro Periperi, em Salvador.

Ampliando suas observações do ano anterior, o Governador Antônio Balbino referiu-se ao aumento de unidades de ensino secundário no estado. Desta forma, apontou:

Em matéria de Ginásios do Estado, encontrámos, na Capital, funcionando, o Severino Vieira, o Duque de Caxias, o João Florêncio Gomes, e a secção Estadual do Instituto Normal. Ampliamos o quadro existente com o Ginásio Góes Calmon em Brotas, que em breve será também internato dentro do programa do PAMESE, destinado a filhos de funcionários públicos estaduais,; o da Polícia Militar, nos Dendezeiros; o Manoel Devoto, no Rio Vermelho; e o Pinto de Carvalho em São Caetano, todos funcionando e já superlotados; e em perspectiva de breve instalação, o 8 de Novembro, em Peripiri. (BAHIA, 1958, p. 20).

Em relação ao interior do estado, o governo apontava como unidades em funcionamento os Ginásios estaduais em Feira de Santana, Jequié, Vitória da Conquista, Cachoeira, Caetité e Santo Amaro, além daqueles criados em Juazeiro, 
Jacobina, Caculé, Itabuna, Canavieiras, Valença e Barreiras. Para o governador, estas unidades levaram a triplicar a possibilidade de atendimento (BAHIA, 1958).

Em 1960, em 194 municípios existentes, somente 76 possuíam estabelecimentos de ensino médio. Destas instituições de ensino médio, 62 eram somente ginasiais e 08 eram ginasiais e colegiais; em nenhum município era somente colegial. Nos estabelecimentos de ensino secundário os cursos eram diversificados: 10 somente básico comercial, 07 comercial básico e técnico, 05 somente técnico, 01 industrial, 01 agrícola e 40 ensino normal (INSTITUTO BRASILEIRO DE GEOGRAFIA E ESTATÍSTICA, 1960).

Em 1961 fundou-se o Ginásio Instituto Bom Conselho, no município de Cícero Dantas, porém uma instituição particular.

\section{Algumas considerações}

Na Bahia, o desenvolvimento do ensino secundário tem um percurso bastante irregular. De seu início, em meados do século XIX, até os anos de 1940, a desorganização do ensino secundário baiano, em que pesem as tentativas de reformas, permanece sem grandes transformações e com uma concentração na capital, no que diz respeito ao ensino público.

0 grande problema, na maior parte do processo histórico do ensino secundário baiano, reside no fato de sua enorme concentração e centralização na capital baiana, Salvador. Na maior parte de sua história, o ensino secundário baiano ficou restrito a Salvador, e em uma única instituição de ensino. Primeiro o Liceu Provincial, depois o Ginásio da Bahia, no início da República, e, por fim, o Colégio da Bahia.

Essa trajetória centralizadora é também excludente, pois impedia que as pessoas do interior baiano tivessem acesso a este nível de ensino, a não ser que se deslocassem para a capital, o que atingia uma pequena camada da população.

A centralização do ensino secundário baiano em Salvador perdurou todo o período, desde sua implantação, no século XIX, até meados do século XX, na década de 1940, já no período republicano. É exatamente este período que podemos considerar como de expansão do ensino secundário na Bahia.

Compreendendo a expansão como o aumento de estabelecimentos de ensino, nossas pesquisas nos levaram aos anos a partir de 1947, período em que um governo democrático assumia e dava abertura ao aumento do número de escolas secundárias na capital eno interior do estado, dando início ao processo de expansão para o interior da Bahia.

Outro elemento importante, mesmo que por um pequeno período de atuação, foi, a partir de 1953, a ação da Campanha Nacional de Escolas da Comunidade (CNEC). Apesar de representar uma via de privatização adotada pelo Estado brasileiro, sua ação teve repercussões importantes, principalmente para esclarecer as ações do Estado.

A ampliação de escolas secundárias públicas na Bahia ocorre após eleições democráticas de um governo baiano. A educação aflorou como um elemento importante no processo de democratização da sociedade, dando partida para a noção da possibilidade de expansão de educação de modo geral e, especialmente, para o ensino secundário, ainda que por número de instituições.

É importante destacar que, particularmente na Bahia, o período foi marcado por uma abertura democrática com a eleição para governador de Otávio Mangabeira, no período de 1947 a 1951. Para assumir a Secretaria de Educação do Estado da Bahia, o governador convidou Anísio Spínola Teixeira, que foi o autor da Reforma da Educação baiana de 1925, que ainda estava vigente.

Esse será, efetivamente, o período - entre 1947 e 1961 - que podemos considerar como aquele responsável por um processo de expansão da educação e do ensino secundário na Bahia, ao qual atribuímos o de maior democratização no estado. 


\section{REFERÊNCIAS}

A ABERTURA dos cursos no G. C. Caldas e E. de Nazaré. Diário de Notícias, Salvador, ano 78, no 15.188, 03 abr. 1953, p. 2.

ALEIXO, Onofre Pinto. Relatório apresentado ao Exmo. Senhor Presidente da República. Salvador: Imprensa Oficial do Estado, 1945.

BAHIA. Lei no 117, de 24 de agosto de 1895. Leis e Resoluções da Assembleia do Estado da Bahia no ano de 1895. Salvador: Typografia do Correio de Notícias, 1895. p. 245-276.

BAHIA. Mensagem do governador Otávio Mangabeira apresentada à Assembleia Legislativa na abertura dos trabalhos da sua Reunião Ordinária em 7 de abril de 1948. Salvador: Imprensa Oficial do Estado, 1948a.

BAHIA. Lei no 130, de 14 de dezembro de 1948. Dispõe sobre a criação de Ginásios Oficiais e Subvenção de outros existentes no interior do Estado. Salvador, 1948b. Disponível em: https://leisestaduais.com.br/ba/leiordinaria-n-130-1948-bahia-dispoe-sobre-a\#: : text=DISP $\%$ C3\%95E\%20SOBRE $\% 20 \mathrm{~A} \% 20$ CRIA\%C3\%87\%C3\%830\%20DE,Art. Acesso em: ago. 2017.

BAHIA. Mensagem do Governador Otávio Mangabeira apresentada à Assembleia Legislativa na abertura dos trabalhos da sua Reunião Ordinária em 7 de abril de 1950. Salvador: Imprensa Oficial do Estado, 1950.

BAHIA. Relatório de Aloisio Short, Secretário da Educação da Bahia. Salvador: Imprensa Oficial do Estado, 1957.

BAHIA. Mensagem do governador Antônio Balbino apresentada à Assembleia Legislativa na abertura dos trabalhos da sua Reunião Ordinária de 1958. Salvador: Imprensa Oficial do Estado, 1958.

BOAVENTURA, E. M. Anísio Teixeira e a autonomia da educação baiana. Revista da Bahia, Salvador, v. 32, n. 31, p. 70-83, jul. 2000.

BOAVENTURA, E. M. Problemas da educação baiana. Salvador: Gráfica Universitária, 1977.

BRASIL. Presidência da República. Casa Civil. Lei no 16, de 12 de agosto de 1834. Ato Adicional de 1834. Faz algumas alterações e addições á Constituição Politica do Imperio, nos termos da Lei de 12 de Outubro de 1832. Rio de Janeiro,
1834. Disponível em: http://www.planalto.gov.br/ ccivil_03/leis/lim/LIM16.htm\#: :text=LEI\%20 N\%C2\%BA\%2016\%20DE\%2012\%20DE\%20 AGOSTO\%20DE\%201834.\&text=1\%C2\%BA\%20 0\%20direito $\% 20$ reconhecido $\% 20$ e,titulo $\% 20$ de\%20Assembl\%C3\%A9as\%20Legislativas\%20 Provinciaes. Acesso em: ago. 2017.

BRASIL. Câmara dos Deputados. Decreto no 19.890, de 18 de abril de 1931. Dispõe sobre a organização do ensino secundário. Disponível em: https://www2.camara.leg.br/legin/fed/ decret/1930-1939/decreto-19890-18-abril1931-504631-publicacaooriginal-141245pe.html\#: : text=Art., sob $\% 20$ regimen $\% 20$ d e \% 20 in s p e c \% C $3 \%$ A $7 \%$ C $3 \%$ A 3 o \% 20 official.\&text $=0 \% 20$ ensino $\% 20$ secundario $\% 20$ compehender\%C3\%A1\%20dous\%20 cursos\%20 seriad os $\% 3 \mathrm{~A} \% 20$ fundamental $\% 20$ e $\% 20$ complementar. Acesso em: ago. 2017.

BRASIL. Câmara dos Deputados. Decreto-lei no 4.244, de 9 de abril de 1942. Lei Orgânica do Ensino Secundário. Disponível em: https://www2.camara. leg.br/legin/fed/declei/1940-1949/decreto-lei4244-9-abril-1942-414155-publicacaooriginal-1pe.html. Acesso em: ago. 2017.

BULCÃO, A .de A. de A. Relatório com que o ILM. e EXM. Sr. Dr. Antonio de Araújo de Aragão Bulcão passou a 23 de março de 1881 à administração da Provincia ao ILM. E EXM. Sr. Conselheiro João Lustosa da Cunha Paranaguá. Salvador: Typografia do Diário da Bahia,1881.

COLEÇÃO de Jornais do ano de 1942 a 1961. Jornal A Tarde. Salvador: Biblioteca Pública do Estado da Bahia.

DIAS, Satyro de Oliveira. Relatório sobre a Instrução Pública no Estado da Bahia. Salvador: Typografia e encadernação do Diário da Bahia, 1894.

DICK, Sara Martha. As políticas públicas para o ensino secundário na Bahia: o Liceu Provincial: 1860-1890. 2001. 280 f. Tese (Doutorado em Educação) - Faculdade de Educação, Universidade Federal da Bahia (UFBA), Salvador, 2001.

FARIAS, Gelásio de Abreu; MENEZES, Francisco da Conceição. Memória Histórica do Ensino Secundário Official na Bahia durante o primeiro século 1837-1937. Salvador: Imprensa Oficial do Estado, 1937.

INSTITUTO BRASILEIRO DE GEOGRAFIA E ESTATÍSTICA (IBGE). Anuário Estatístico do Bra- 
sil: Ano XIII-1952. Rio de Janeiro, 1953. Disponível em: https://biblioteca.ibge.gov.br/bibliotecacatalogo?id=720\&view=detalhes. Acesso em: 20 mar. 2019.

INSTITUTO BRASILEIRO DE GEOGRAFIA E ESTATÍSTICA (IBGE). Anuário Estatístico do Brasil: Ano XXI-1960. Rio de Janeiro, 1960. Disponível em: https://biblioteca.ibge.gov.br/visualizacao/ periodicos/20/aeb_1960.pdf. Acesso em: jul. 2019.

JESUS, Andreia Reis de. Colégio Estadual da Polícia Militar - primeiros tempos: formando brasileiros e soldados (1957-1972). 2011. Dissertação (Mestrado em Educação) - Faculdade de Educação, Universidade Federal da Bahia (UFBA), Salvador, 2011.

LIMA, Débora Kelman de. 0 banquete espiritual da instrução: o Ginásio da Bahia, Salvador: 1895-1942. 2003. 175 f. Dissertação (Mestrado em História) - Programa de Pós-Graduação em História, Universidade Federal da Bahia (UFBA), Salvador, 2003.

MATTOSO, Kátia. Bahia Século XIX - uma Província no Império. Rio de Janeiro: Nova Fronteira, 1992.

NUNES, Antonietta de Aguiar. As reformas educacionais na província da Bahia durante o Império brasileiro. Revista Gestão em Ação, Salvador, v. 2, n. 1, p. 73-98, jan./jun. 1999.

NUNES, Antonietta de Aguiar. Educação na Bahia durante a primeira república. Revista do Instituto Geográfico e Histórico da Bahia, Salvador, n. 96, p. 219-252, 2001.

NUNES, C. 0 "velho" e o "bom" ensino secundário: momentos decisivos. Revista Brasileira de Educação, Rio de Janeiro, n. 14, p. 35-60, maio/ago. 2000.

O ENSINO secundário. Diário de Notícias, Salvador, ano 74, no 14239 , p. 4, 25 jan. 1950.

O GOVERNO e os Ginásios. Diário de Notícias, Salvador, ano 78, no 15.188, 25 jul. 1953, p. 4.

REVISTA BRASILEIRA DE ESTUDOS PEDAGÓGICOS, v. 6, n. 17, nov. 1945.

SILVA, Ronalda Barreto et al. A atuação da Campanha Nacional de Escolas da Comunidade - CNEC na educação baiana (1953-1964). In: SIMPÓSIO NACIONAL DE HISTÓRIA, 22., 2003, João Pessoa. Anais eletrônicos [...]. João Pessoa, 2003. Disponível em: http://www.snh2013. anpuh.org/resources/anais/anpuhnacional/S.22/ ANPUH.S22.599.pdf. Acesso em: out. 2019.

TAVARES, Luís Henrique Dias. Duas reformas da educação na Bahia: 1895-1925. Salvador: MEC/ Centro Regional de Pesquisas Educacionais da Bahia, 1968.

TEIXEIRA, A. Relatório da Inspetoria Geral do Ensino do Estado da Bahia, apresentado como Anuário do Ensino do Estado da Bahia. Salvador, 1925.

TEIXEIRA, Anísio. Educação, Saúde e Assistência no Estado da Bahia em 1948. Relatório apresentado pelo Sr. Anísio Teixeira, Secretário de Educação e Saúde, ao Sr. Governador do Estado. Salvador: Imprensa Oficial do Estado, 1949. Disponível em: http://www.bvanisioteixeira. ufba.br/artigos/educacao10.html. Acesso em: jul. 2018.

TEIXEIRA, Anísio S. Educação Média. [194-?]. Mimeografado.

Recebido em: 15/04/2020

Revisado em: $24 / 08 / 2020$

Aprovado em: 30/08/2020 